\title{
Inheriting Sixty Years of Essence in Adult Education and Forging the New Ecology of ICT Online Education-Exploration of Continuing Education Reform and Development in School of Online Education at Beijing University of Posts and Telecommunications (BUPT)
}

\author{
Han-Xu SUN, Li-Min DENG, Chang-Rui QU, Ai-Yang ZHANG
}

Faculty of School of Online Education at Beijing University of Posts and Telecommunications

Keywords: distance education; development model

\begin{abstract}
China's distance education has gone through 20 years since it was founded. Socialism with Chinese characteristics has stepped into a new era. The principal contradiction facing Chinese society have been transformed into the people's ever-growing needs for a better life and unbalanced and inadequate development. In the new era, people's demand for education is no longer satisfied with the access to education, but to pursue better education. In the new era online education has responsibilities and it also has the ability to shoulder the historic mission of education balance and high quality of education. How to build and develop better distance education is a problem that distance educators must face and solve. The authors of this article proposes the way to develop distance education with the characteristics of BUPT by analyzing the mode of running the school of online education at Beijing University of Posts and Telecommunications and implements the requirement of "perfecting continuing education, speeding up the construction of a learning society, and vigorously improving the quality of the nation” with the distance education model.
\end{abstract}

\section{Introduction}

The year of 2018 marks the 60th anniversary of the establishment of adult education in our university. We continuing education professionals must clearly see that our country is marching towards the grand goal of completing the building of a moderately prosperous society and realizing "the two centenary goals". In this great historical process, while faced with insisting on quality and profitable development, we are also shouldering the responsibility of building a lifelong learning society, completing the comprehensive reform of continuing education and better serving the industry, the students, and the economic and social development of the capital under the guidance of the Ministry of Education.

The 60 years of development and accumulation have given Beijing University of Posts and telecommunications (BUPT) a profound history and an excellent style of running a school. The adult education of BUPT will keep pace with the pulse of the times and strive to develop online education, in order to build an overpass for vocational education, non-diploma education, and general higher education and it will transform into a school that emphasizes on both curriculum education and non-curriculum education instead of only focusing on curriculum education, forming "a dynamic core”, "two engine drive”, "three system support”, "four development guarantees", and an open, plural, multi-layered, and diverse adult education system to strive for the national first-class school of online education.

The emphasis of "a dynamic core" lies in the quality of education. Quality is the lifeline for 
the development of adult education at BUPT, and it is also the bottom line that we have always adhered to since its establishment 60 years ago. We will ensure quality, highlight features, and comprehensively improve the level of curriculum education. On the one hand, it strictly controls the enrollment of students and continuously improves the quality of students. It supervises the distance off-campus learning centers and correspondence teaching centers to rigorously review new student enrollment qualifications and carefully audits enrollment materials; On the other hand, it actively promotes cooperation with high-quality enterprises and helps the distance off-campus learning centers to establish better cooperative relationships with high-quality enterprises so that the quality of students is guaranteed from the very beginning.

"The two engine drive" is the development of both curriculum education and non-curriculum education. "The first engine drive" is that we will continue to broaden the field of service cooperation in curriculum education, build a multi-win-win model of school-enterprise cooperation, improve the quality of employees and help upgrade the industry of adult education; at the same time, we will implement social service responsibilities of universities, respond to social needs, and actively participate in public assistance programs; what's more, we will help students to build and realize their dreams. We will also start the credit bank construction, build an "overpass" between various forms of learning, such as curriculum and non-curriculum education, and strive to become a practitioner that promotes the integration of multiple forms of education.

"The second engine drive" is non-curriculum education that will use the "U-Learning Online" education service platform as an entry point, carefully building an online education ecology, integrating high-quality industry resources through platforms, and providing platforms, courses, and operations-related services. We will absorb high-quality courses from universities, industries, companies, and vocational colleges and work together with excellent teachers in various fields with rich training experience to create courses of new technologies, innovation and entrepreneurship, professional qualification certification, general knowledge, management marketing and other course series to meet the various needs of training in the field of information and communication. By the end of 2018, when the construction of U-Learning Online is completed, in addition to supporting basic registration, course selection, payment, learning, examination, and certification, it will also support flexible curriculum promotion strategies, partner classification management strategies, mutual recognition strategies of credits and certification, etc. More importantly, it will enable personalized learning services and facilitate social services based on data and relational calculations. U-Learning Online has designed an open and flexible model of cooperation and service based on the basic elements, such as courses, faculty, platform, certificates, credits, etc. It has become an advantageous support for linking curriculum education with non-curriculum education and serving lifelong learning. Since then, a two-wheeled drive for adult's curriculum education and non-curriculum education will emerge.

"Three system support": The first is discipline support. We will build an educational technology specialty with BUPT's characteristics based on the research strength and brand advantages of BUPT in the field of information technology that emphasizes on developing online education technology, mobile/ubiquitous learning, virtual experimentation, learning analysis and other research fields into the top level in China. In terms of expanding academic influence, it is necessary to build a brand of " Education Technology of BUPT" and strive for national recognition and influence in the field of distance education and training education; at 
the same time, we will spear no efforts to build an educational technology discipline with BUPT's characteristics in 2020, striving to complete the construction of the first-level discipline institution in education granting master degrees, and endeavor to establish the second-level discipline institution granting doctorate degrees.

The second is the support of class resources. We will continue to increase our investment in high quality educational resources. We will rely on the Institute of Educational Technology as the mainstay and fully construct excellent digital learning resources for adult education of BUPT

in three aspects: the systemic nature of the subject system, the scientificity of research and development methods, and the lead edge of technology. The focus of the systemic nature of the subject system is to increase the number of high quality courses and improve the coverage of excellent courses. It is expected that after 3-5 years of concentrated curriculum development, a systematic web-based curriculum system will be developed to coordinate the development of science, technology, and management in various fields and highlight the advantages of BUPT in information science. In terms of the scientificity of research and development methods, it will continue to adhere to the "learning based on activity" idea, pay more attention to the system interaction design and teaching strategy research in the curriculum research and development process and guarantee the scientificity of the curriculum research and development methods to create online courses that are more in line with the characteristics of adult learners; moreover, as to the leading edge of technological means, with the advantages BUPT has in the fields of Internet of Things and cloud computing, we will actively explore the application of leading edge technologies such as virtual reality and augmented reality in adult continuing education, build an industry-based ubiquitous learning education resource system, and realize the deep and close integration of information and communication technologies and adult education.

The third is the support of smart campus. The typical application of distance learning represented by MOOC has already had a far-reaching impact in the field of higher education in China, and distance learning will become an important part of "socialized and lifelong" learning. We will take the existing online teaching platform as an entry point, combine the strengths of the school's superior disciplines, and actively explore and solve the multi-campus education informatization methods that are in line with BUPT's characteristics; meanwhile, we will try to use digital TV broadcasting technology and network teaching service support system to realize real-time and interactive teaching based on multi-campus in order to contribute to further improving BUPT's teaching informatization infrastructure, building the teaching informatization service system that conform to the laws of education and teaching and follow the development trend of education informatization.

"Four development guarantees": The first one is the guarantee of teachers and administrative staff. The school of Online Education at BUPT will build a team of teachers with strong political thinking, high academic level, reasonable structure, and full of vitality as the school's long-term and strategic tasks. In the construction of the teaching resource, with the discipline construction and professional restructuring as the most important emphasis, and with the overall goal of optimizing the overall structure of the teaching staff, we will focus on accelerating the development of a group of academic leaders. We will adhere to the combination of introduction and cultivation and actively advance the overall construction of teaching team; At the same time, based on the actual situation, we will set appropriate business positions, give more freedom and opportunities to business education staff, improve 
the personnel structure of the management team, further improve the work style, enhance management methods, and raise the management level and service quality.

The second is platform system guarantee. We will stabilize and perfect the long-distance curriculum education platform, realize and open the mutual recognition of curriculum and credits on the platform, and continue to track the development progress of the Sakai open source system and the problems it has solved. The existing running teaching system will be upgraded accordingly in terms of the specific situation, . The educational platform will make business adjustments based on changes in policy. With the development of the open curriculum platform, the function of mutual recognition of credits in curriculum education has been implemented; at the same time, to meet the mobile needs of students and customers, improve the user experience, and enhance the market competitiveness of BUPT's adult education, we will also promote the development and application of mobile apps, and strive to achieve the goal that $90 \%$ of the existing student-side functions are implemented on the mobile terminal, allowing students to learn at anytime and anywhere.

The third is the guarantee of student's learning support service and teaching support service. During the service, we spare no effort to deepen the connotation of students' learning and teaching support services, and to create a concept of "cultivating students throughout the entire process and whole staff nurturing students”. We will continue to innovate ways of providing service and improve the efficiency and proficiency of supervising and helping students from the perspective of our school and various distance learning centers. We will constantly implement the "student-centered" concept into platform design, discipline construction, instructional design and organization, teaching management process design, question answering, virtual campus construction etc.;meanwhile we will constantly enhance student's learning support services of the academic and non-academic to optimize students' learning experience so that students can fully experience the "learning happily, learning efficiently" and "learning well".

The fourth is that we will establish a guarantee for the normal assessment system. We will strengthen the management of distance off-campus learning centers, establish and improve the management rules and systems of them, and follow the assessment methods of off-campus learning centers to standardize school-running. In addition, we will strengthen the enrollment of off-campus learning centers and the extraction and excavation of work data such as teaching and students' learning support to provide more detailed feasibility guidance for its development, allowing the off-campus learning centers to carry out more targeted work; at the same time, it enables distance off-campus learning centers to serve as a medium for introducing BUPT in various of places through the construction of standardized distance off-campus learning centers.

\section{References}

[1]BUPT. Base in industry inheritiance, build new ecology of online education with a history of 60 years[OL]https://www.sohu.com/a/209463630_414933[2017-12-09].

[2]RenminWang. BUPT:“Network+”promoting cultural and ideological progress and Student entrepreneurship[OL]http://edu.people.com.cn/n/2015/0507/c227065-26964256.html.[2015-0 5-07].

[3]Ge Zi-gang. Research on the College English online course in distance Education[J]. Modern Educational Technology, 2010, 20(9):85-90. 